\title{
Narrativas de familiares de autistas de Capsi da região metropolitana do Rio de Janeiro: participação, protagonismo e barreiras ao cuidado
}

\author{
Narratives of family members of Capsi's autistic patients from the \\ metropolitan region of Rio de Janeiro: participation, protagonism \\ and barriers to care
Rossano Cabral Lima1, Maria Cristina Ventura Couto 2 , Bárbara Costa Andrada2 ${ }^{2}$ Pedro Henrique Corrêa', Alda Carla Alves Cardozo'

DOI: $10.1590 / 0103-11042020 E 313$

\begin{abstract}
RESUMO A atenção psicossocial aos familiares dos usuários dos serviços substitutivos é um dos principais desafios da Reforma Psiquiátrica brasileira. O presente trabalho é fruto de pesquisa avaliativa qualitativa, envolvendo a realização de grupos focais com familiares de crianças e adolescentes autistas atendidos em Centro de Atenção Psicossocial Infantojuvenil (Capsi) da Região Metropolitana do Rio de Janeiro. O artigo analisou duas categorias extraídas das narrativas dos familiares: o protagonismo e a participação no cuidado oferecido pelo Capsi, e as barreiras no acesso e na continuidade do cuidado. Vários familiares relatam participação em distintas formas de ativismo e na luta por direitos, mas apontam a necessidade de ampliar o envolvimento no cuidado psicossocial dos filhos. Relatam experiências positivas nos Capsi, mas se queixam de dificuldades relacionadas com o acesso, envolvendo transporte, os horários de funcionamento do serviço, a frequência dos atendimentos e a falta de manutenção e a precariedade do espaço físico. Uma maior aproximação dos Capsi com os familiares - por meio da valorização de suas falas, do acolhimento ao seu sofrimento e do estímulo e respeito a sua auto-organização - pode ser estratégica para a preservação e a consolidação das conquistas da Reforma Psiquiátrica brasileira e para a superação de obstáculos no cumprimento do mandato psicossocial desses serviços
\end{abstract}

PALAVRAS-CHAVE Transtorno autístico. Cuidadores. Centros de Atenção Psicossocial.

1 Universidade do Estado do Rio de Janeiro (Uerj), Instituto de Medicina Social (IMS) - Rio de Janeiro (RJ), Brasil. rossanolima1@gmail.com

2 Universidade Federal do Rio de Janeiro (UFRJ), Instituto de Psiquiatria (Ipub) - Rio de Janeiro (RJ), Brasil.

\begin{abstract}
Psychosocial care for parents of substitute services' patients is one of the main challenges of the Brazilian Psychiatric Reform. The present work is the result of qualitative evaluative research, involving focus groups with family members of autistic children and adolescents treated at Child and Adolescent Psychosocial Care Centers (Capsi) in the Metropolitan Region of Rio de Janeiro. The article analyzes two categories from the narratives provided by family members: their protagonism and participation in the context of Capsi, and the barriers in access and continuity of care. Several family members report participation in different forms of activism and in the fight for social rights, but point out the need to expand their involvement in the child's psychosocial treatment. They report positive experiences at the Capsi, but complain about difficulties involving transportation, services opening hours, frequency of therapies, and the precariousness of the physical space. A closer relationship between the Capsi and family members - through the valuing of their speeches, the care of their suffering and the encouragement and respect for their self-organization initiatives - can be strategic for the preservation and consolidation of the Brazilian Psychiatric Reform achievements and for overcoming obstacles in fulfilling the psychosocial mandate of those services.
\end{abstract}

KEYWORDS Autistic disorder. Caregivers. Mental health centers. 


\section{Introdução}

Dentre os desafios enfrentados no processo de Reforma Psiquiátrica no Brasil, destaca-se o da relação com os familiares dos usuários dos serviços comunitários de saúde mental. Do ponto de vista político, as décadas de 1980 e 1990 foram marcadas por embates entre o movimento da luta antimanicomial e a Associação de Familiares de Doentes Mentais (AFDM), defensora do modelo hospitalocêntrico. Entretanto, as primeiras associações de familiares de autistas, surgidas nos anos 1980, não tiveram maior influência naqueles debates e disputas. Já os anos 2000 testemunharam o fortalecimento do ativismo de grupos de familiares de autistas, inicialmente com pouca interação com a Rede de Atenção Psicossocial (Raps), e posteriormente com posições antagônicas a essa ${ }^{\mathbf{1}, \mathbf{2}}$.

Do ponto de vista dos equipamentos da Raps, estudos mais recentes envolvendo familiares de usuários de Centros de Atenção Psicossocial (Caps) têm reconhecido a sobrecarga objetiva e subjetiva ${ }^{3}$ experienciada por eles e apontado para a necessidade de estratégias que visem melhorar sua qualidade de vida, por meio de grupos de ajuda mútua e educação em saúde, entre outros ${ }^{4,5}$. A corresponsabilização dos familiares pelo cuidado dos usuários demanda maior suporte a eles por parte dos serviços comunitários ${ }^{6}$, cujas equipes devem estar mais próximas das famílias para compreender suas histórias, dilemas, conquistas e biografias, colaborando para que estas enfrentem de modo menos sofrido as adversidades impostas ao seu cotidiano ${ }^{7}$.

Pesquisas envolvendo familiares de crianças e adolescentes tratados nos Centros de Atenção Psicossocial Infantojuvenil (Capsi) são mais escassas, especialmente as que têm como foco familiares de usuários autistas ${ }^{8}$. Estudo epidemiológico de caráter avaliativo envolvendo familiares em Capsi da cidade do Rio de Janeiro revelou satisfação com o serviço oferecido, havendo queixas em relação à falta de atendimento individual e à infraestrutura. Nesse mesmo estudo, entre as diversas condições atendidas no Capsi, o diagnóstico de autismo foi o único relacionado à satisfação dos familiares com o serviço de modo global ${ }^{9}$.

Com finalidade de contribuir para a ampliação de estudos sobre familiares de autistas, em artigo anterior ${ }^{\mathbf{1 0}}$ abordamos duas categorias de análise a partir de narrativas recolhidas de Grupos Focais (GF) realizados com familiares de Capsi: a 'percepção dos familiares sobre o autismo' e 'experiências de sobrecarga na lida cotidiana'. Foram analisados os modos peculiares dos familiares descreverem e compreenderem o autismo, a apropriação particular que fazem do discurso dos profissionais e a construção de uma expertise leiga na lida com os filhos.

Do conjunto de narrativas oriundas dos GF, outras duas categorias se destacaram e serão objeto do presente estudo. A primeira diz respeito ao envolvimento dos familiares no cuidado oferecido pelo Capsi, seja no sentido de seu protagonismo, ativismo e mobilização por direitos, seja no sentido de sua inclusão ativa no Projeto Terapêutico Singular (PTS). A outra, está relacionada com as dificuldades no acesso e na continuidade do cuidado, que comprometem a lida cotidiana e incidem no aumento da sobrecarga.

No Brasil, a luta dos familiares por 'direito ao tratamento' se deu em dois tempos. O primeiro abrange a criação da Associação de Amigos do Autista de São Paulo (AMA), em 1983, e a fundação da Associação Brasileira de Autismo (Abra), em 1988. Essas associações surgiram com os objetivos principais de conscientização sobre o transtorno, troca de experiências e treinamento de profissionais e pais, e com demandas por políticas públicas que se limitavam às áreas da deficiência, assistência social e educação ${ }^{11,12}$. Na virada da década de 1990 para os anos 2000, iniciou-se um segundo momento do ativismo de familiares, agora também engajados na proposição de legislação e de locais de tratamento específicos para autistas $^{13}$. Esses movimentos estão diretamente relacionados com a crítica ao atendimento de autistas em Caps e Capsi, tendo importante protagonismo do estado do Rio de Janeiro ${ }^{\text {14-17, }}$ e grande visibilidade e influência na definição 
da pauta política em nível municipal, estadual e federal. Apenas recentemente começaram a surgir associações que defendem a atuação da Raps no cuidado aos autistas, sem desmerecer os serviços especializados ${ }^{\mathbf{1 8}}$.

Ao lado da temática da mobilização e ativismo, há a questão do lugar dos familiares no tratamento do filho autista. Uma abordagem ampliada da relação de cuidado, que vise 'cuidar de quem cuida'19, além de valorizar as expertises específicas e empíricas desses familiares na tradução do autismo de seus filhos em contexto ${ }^{20}$, pode se configurar um potente recurso para o avanço e aprimoramento das políticas públicas de saúde mental. Iniciativas inovadoras - como as experiências de recovery e empoderamento ${ }^{\mathbf{2 1}, 22}$ - que ampliam o protagonismo de usuários e familiares em ações de cuidado, pesquisa e de sustentação de políticas públicas em saúde mental ainda não constam na agenda de saúde mental de crianças e adolescentes. Apesar da recomendação de inclusão dos familiares de usuários dos Caps no projeto terapêutico ${ }^{4,23}$, o que é ainda mais pertinente no caso de crianças e adolescentes, há evidências de que o cuidado aos familiares em muitos Capsi está aquém do que eles próprios julgam como ideal, frequentemente ocorrendo de forma episódica e não sistemática ${ }^{\mathbf{2 4}, 25}$. A despeito disso, os responsáveis tendem a reconhecer o suporte proporcionado pelo serviço, destacando os espaços grupais como os mais relevantes para suporte mútuo, compartilhamento de experiências, troca de informações, e, consequentemente, alívio de sofrimento ${ }^{26-28}$.

A segunda categoria que será abordada neste estudo diz respeito às dificuldades encontradas no acesso e na continuidade dos cuidados no Capsi, que são diretamente relacionadas com a experiência de sobrecarga, abordada no artigo anterior ${ }^{10}$. $\mathrm{O}$ acolhimento inicial por parte da equipe pode servir como contrapeso às dificuldades encontradas para a chegada ao serviço ou na sustentação do tratamento em médio e longo prazo ${ }^{29}$. Familiares de Caps - em sintonia com pesquisas avaliativas desses serviços ${ }^{\mathbf{3 0}}$ - têm apontado avanços, mas também problemas em relação a infraestrutura, recursos financeiros e número de profissionais ${ }^{31}$.

Dessa forma, o presente artigo tem como objetivo examinar, inicialmente, como os familiares vêm se mobilizando e como avaliam sua inserção no projeto terapêutico dos filhos, dado que este implica necessariamente o apoio aos responsáveis. Logo em seguida, o artigo investiga os obstáculos encontrados pelos familiares no acesso ao serviço e na continuidade do cuidado psicossocial.

\section{Material e métodos}

Este artigo resulta de pesquisa maior, qualitativa, de caráter avaliativo, envolvendo profissionais e familiares de 14 Capsi da Região Metropolitana do Rio de Janeiro ${ }^{32,33}$. Em relação aos familiares, foram realizados $3 \mathrm{GF}$, organizados por região, cada um agrupando familiares dos Capsi da capital (Rio de Janeiro), da Região Metropolitana I (Baixada Fluminense) e da Região Metropolitana II (Niterói, São Gonçalo e Itaboraí). No total, participaram 29 familiares, sendo 24 do sexo feminino e 5 do sexo masculino.

Os participantes foram selecionados por amostragem intencional; cada Capsi indicou entre $2 \mathrm{e}$ 4 familiares de crianças e adolescentes autistas em tratamento por pelo menos 6 meses. Os GF foram realizados em local de fácil acesso, com duração média de 1h30, e cerca de 7 a 12 familiares participantes. Os áudios foram gravados e transcritos. Cada familiar será designado pela letra F, seguida de um número, de acordo com a ordem de aparecimento de suas falas no texto.

O presente artigo aborda duas categorias, quais sejam: o protagonismo e a participação dos familiares nos processos de cuidado, e as barreiras no acesso e na continuidade do tratamento no Capsi. Para este fim, foram extraídas, da totalidade do material da pesquisa maior, as narrativas mais diretamente relacionadas com esses dois temas que, posteriormente, foram analisadas pelo grupo de pesquisadores.

A pesquisa foi aprovada pelo Comitê de 
Ética em Pesquisa do Instituto de Psiquiatria da Universidade Federal do Rio de Janeiro - Ipub/ UFRJ (parecer $n^{\circ} 81$ Liv3-11) e pelo Comitê de Ética em Pesquisa da Secretaria Municipal de Saúde e Defesa Civil do Rio de Janeiro (CAAE: 0045.0.249.314-11). Não houve exigência desse processo pelos demais municípios.

\section{Resultados e discussão}

\section{Protagonismo e participação nos processos de cuidado}

Esta categoria se refere ao envolvimento dos familiares no cuidado oferecido pelo Capsi e se subdivide em dois temas parcialmente interligados. O primeiro diz respeito ao protagonismo, ativismo e mobilização por direitos, tanto na dimensão micropolítica do serviço quanto na esfera macropolítica do município, do estado ou do país. O segundo se refere a sua inclusão ativa no PTS, abrangendo principalmente sua escuta, apoio e orientação pelos profissionais, por meio de participação em espaços individuais ou grupais do Capsi.

\section{Ativismo, mobilização e direitos}

Alguns familiares relataram fazer parte de movimentos ou estarem articulando a criação de associação de pais em seu município, enfatizando as estratégias coletivas de luta por direitos e políticas públicas:

Eu estou montando uma associação de pais, porque a Baixada é muito carente disso. Nós temos que nos fortalecer pra poder brigar pelos nossos filhos. De pais de autistas. O nosso logotipo foi feito por um autista, um desenho lindo que um autista aluno lá da escola fez. (F1).

Quando a gente abre mão de um direito adquirido, a gente acaba fazendo com que outras pessoas não tenham acesso. Então eu acho muito mais fácil a gente se juntar e lutar por uma coisa melhor dentro daquilo que é uma estrutura que é do governo, que tem que tutelar essa coisa. Você está entendendo? Essa coisa da saúde é prioridade pra eles, tá na Constituição, então a gente tem que lutar é por isso. [...] Se a gente ficar 'não, eu vou tratar tudo por vias particulares', quando você buscar a via pública, que vai ser necessário em algum momento, você vai ter dificuldade muito maior pra conseguir. (F3).

É possível perceber o destaque dado pelos familiares à presença em espaços político-institucionais como caminho para a concretização do direito à saúde e outros direitos sociais, por meio de legislação específica ou atos do executivo, embora reconhecendo as limitações e os vícios presentes nessa esfera:

Eu acho que a gente tem que buscar a via pública, tem, tem que falar com o legislador, tem que arrumar uma costa quente, mas eu acho que a gente tem que começar a fazer alguma coisa entre nós, dentro do espaço do Capsi, pra demonstrar e pra tocar naqueles que tem interesse de aparecer, porque esses caras querem aparecer. (F3).

Eu e mais um grupo de mães estamos se organizando pra fazer as coisas. A gente já pediu uma audiência pública lá [...]. A gente tem que entrar, nessas coisas que a gente tem que brigar né, procurar os nossos direitos, porque senão a coisa não flui, a coisa não anda. (F2).

Aonde a gente está conseguindo ter um pouco de voz: no Capsi. Agora tem uma audiência pública marcada dia treze, tem uma mãe também lá do Capsi que tá em contato com um vereador pra marcar uma audiência com ele, pra ver, pra estar buscando todos os laços. (F4).

Os trechos destacados revelam a autopercepção de parte dos familiares como atores políticos; contudo, tais iniciativas, envolvendo a criação de associações e a presença em audiências públicas, ainda se mostram incipientes, carecendo de maior sustentação, apoio e parceria entre os próprios familiares e por parte dos trabalhadores dos serviços. 


\section{Participação no tratamento e cuidado aos familiares}

Os familiares compreendem sua participação no projeto terapêutico e sua relação com os profissionais como condições fundamentais para que haja avanços no tratamento realizado pelos filhos no Capsi:

Porque o principal no tratamento do autista é a participação dos pais. Porque se os pais não se engajarem nisso fica difícil. (F5).

Eu rejeitei umas três ou quatro psicólogas, a Dra. foi ó, dez, consegui. E meu filho teve um ganho muito grande com isso, então é assim mesmo, porque tem a identificação do paciente com o profissional, e tem a nossa aceitação também. (F3).

Você pode ter certeza de uma coisa, os pais que estão aqui, todos eles participam do tratamento do filho. Não vai falar mal dos Capsi assim em relação a tratamento, porque aquele pai que fala que aquele Capsi não adianta, não melhora, é aquele que espera um milagre. Porque o tratamento do autista tem que ter a participação da família. Tem que ter integração. (F5).

Recente revisão integrativa da literatura sobre Capsi revelou o quanto a assistência aos familiares dos usuários ainda se mostra deficitária em muitos serviços, ressaltando a importância que o PTS não abarque somente a criança ou o adolescente ${ }^{24}$. Em estudo realizado em Capsi de Cascavel (PR), familiares apontaram que o encontro com os profissionais ocorre quando há procura por ajuda ou quando o serviço os convida para participar de alguma atividade. Gostariam, entretanto, de estar mais próximos da equipe multiprofissional seja para esclarecimentos sobre as relações intrafamiliares e o comportamento do usuário no domicílio, seja para se sentirem em condições de apoiar as necessidades expressas e vivenciadas pelos filhos ${ }^{25}$.

Em nosso estudo, muitos familiares reconheceram o Capsi como local no qual obtiveram amparo e suporte:
Porque quando eu fui pro Capsi eu estava desesperada. Eu não dormia, entendeu? Eu tive esse apoio, a família teve esse apoio deles. (F6).

Foi aqui que eu fui acolhida quando descobri que o meu filho era autista, fiquei perdida. (F7).

Eu falo que eu preciso de ajuda, peço mesmo, Capsi tá comigo, me ajuda... [...] Digamos assim, hoje eles são o meu suporte. (F8).

De forma semelhante, pesquisa em Capsi de Fortaleza (CE) apontou que muitos familiares reconheciam o apoio, a orientação e o alívio oferecidos pelo serviço no decorrer do tratamento dos filhos, reduzindo sua sensação de impotência ${ }^{28}$. Outro estudo, em Capsi do Rio Grande do Sul, utilizando instrumentos de avaliação de qualidade de vida, encontrou pontuações baixas em pais ou outros cuidadores, sugerindo a presença de intenso sofrimento e sobrecarga nesse grupo ${ }^{34}$.

Os familiares ressaltam a importância dos atendimentos grupais como espaços de expressão de sentimentos, experiência de pertencimento, e de compartilhamento de dificuldades, conhecimento e ideias a respeito de si e de seus filhos.

Aqui é assim: enquanto as crianças são atendidas ali fora, nós ficamos nessa sala ou em outra sala, com uma psicóloga. Uma hora eles ficam brincando e nós ficamos trocando ideias. É o grupo de pais que chama. O meu é terça e quinta, toda semana tem. (F7).

A mesma coisa que tem com os adolescentes também tem com os pais. Faz um grupo. A gente faz uma reunião com a psicóloga e depois almoça todo mundo junto. (F9).

Eu me sinto fazendo parte lá por quê? Porque além de ter o grupo da família - que é toda última quarta-feira do mês - todos os profissionais lá me chamam pelo nome. [...] A doutora participa dessas reuniões, a psicóloga. Ela também participa, ela conversa, ela pergunta, e também já gravou o nome. Assim, a atenção é espetacular. (F6). 
Em sintonia com as narrativas encontradas em nossa pesquisa, em estudos envolvendo familiares em Capsi da Paraíba, os grupos foram destacados como espaços privilegiados de cuidado, apoio mútuo e compartilhamento de experiências, facilitando as trocas entre os responsáveis e o Capsi e reforçando a compreensão do potencial terapêutico das próprias relações familiares. Além disso, os grupos de medicação foram citados como momento de pactuações, esclarecimentos e troca de informações sobre os psicofármacos utilizados pelos filhos ${ }^{26,27}$. Por outro lado, pesquisa realizada em Capsi no estado de São Paulo mostrou que, em pouco mais da metade dos prontuários, não havia registro de conduta terapêutica destinada à inclusão dos pais ou outros familiares nos projetos terapêuticos. Apesar dessa lacuna de informação, o principal espaço terapêutico destinado às mães e aos pais foram os grupos, que parecem ter objetivos e arranjos distintos em cada serviço, incluindo grupos de orientação, apoio e oficinas, entre outros ${ }^{35}$.

Por fim, é importante ressaltar o destaque dado nos trechos acima a uma categoria profissional em particular, a dos psicólogos. Estudos têm apontado os psicólogos como a categoria de nível superior com maior representatividade nos Caps, inclusive em cargos de gestão ${ }^{29,36}$. O destaque dado a esses profissionais pelos familiares de nossa pesquisa, por um lado, pode apontar a potência dessa categoria, mas, por outro, pode indicar uma especialização excessiva e um esvaziamento da função de escuta dos familiares por outros membros da equipe.

\section{Barreiras ao cuidado}

Esta categoria se refere a aspectos das narrativas dos familiares que enfatizam os obstáculos encontrados no acesso ao serviço e no acolhimento inicial pelos profissionais, assim como às dificuldades para dar continuidade ao tratamento no decorrer do tempo, abrangendo questões relacionadas com o deslocamento até o Capsi, e problemas de infraestrutura e de recursos humanos no serviço.

\section{ACESSO E ACOLHIMENTO}

Tendo em vista a importância da família na construção do cuidado dos usuários dos Capsi, é preciso valorizar a percepção dos familiares quanto às barreiras oferecidas pela Raps, priorizando os aspectos do acolhimento, do cuidado e do acesso aos serviços de saúde. Como apontado em artigo anterior ${ }^{31}$, há escassez de publicações contendo avaliações detalhadas dos funcionamentos dos Capsi, o que dificulta a análise do atual estado geral da rede.

$\mathrm{O}$ acesso se refere a tudo que facilita ou restringe o uso dos serviços ou recursos de saúde por seus potenciais usuários ${ }^{36}$. Já o acolhimento é entendido como o processo que se inicia no primeiro contato dos profissionais com o usuário e sua família, quando serão definidos os passos seguintes, incluindo a avaliação e a discriminação da demanda. Dessa forma, o acesso e o acolhimento constituem distintas faces do mesmo processo.

Nesse tema, diversos familiares apontaram a rapidez com que foram atendidos e elogiaram o acolhimento pelo Capsi, por vezes atribuindo isso à 'sorte' e revelando o desconhecimento que tinham sobre esses serviços:

Eu já liguei, fui muito bem atendida, foi logo marcada uma entrevista com a Dra. Primeiro a gente vai sozinho, conversa tudo que a gente passa com a criança. Depois ela marca um dia para levar a criança para eles avaliarem, e depois começa, 0 que é chamado permanência. [...] Eu acho que eu tive sorte nesse sentido, principalmente, que eu era leiga, nunca ouvi falar, não sabia porque não tem muita informação sobre isso. Assim que me falaram que existia Capsi, uma conhecida minha me deu o número e falou: - Liga para lá! (F11).

Há, contudo, muitos obstáculos que já se iniciam no trajeto até o Capsi. Como nem sempre 
há vaga ou equipamentos de saúde mental infantojuvenil perto de sua residência, grandes deslocamentos podem ser exigidos. Sendo assim, o benefício do passe livre nos transportes públicos é indispensável para muitos casos.

Eu moro lá em Campo Grande, Santa Margarida, então eu tinha que pegar três conduções com ele. Então era difícil, tinha vezes, tinha semana que nem dava, era difícil mesmo. (F12).

Eu pego a van, sempre paguei a minha e antes eu pagava a do [meu filho]. É um absurdo porque eu sei que ele tem o direito dele! Outro dia eu mostrei o cartão e entrei e a van encheu e ele [motorista] falou assim: Põe ele no colo! Aí eu falei: - Por que eu vou por ele no colo? [...] Aí peguei o telefone, liguei para cooperativa e falaram: - Não, senhora, ele tem o direito sim! A gratuidade é dele. (F7).

Eu não consigo entender, eles dão o passe livre, a Barcas S.A. é concessionária que presta serviço pro governo, por que que a Barcas S.A. não deixa o passe livre passar? (F3).

As dificuldades de deslocamento se apresentam, dessa forma, como uma barreira relevante na acessibilidade ao serviço. $\mathrm{Na}$ época da realização da pesquisa, a Lei ${ }^{\circ}$ $12.764 / 12$, que reconhece o autista como pessoa com deficiência, e os decretos do estado e do município do Rio de Janeiro (ambos de 2016), estabelecendo a gratuidade no transporte para pessoas com deficiência, ainda não existiam. Se a criança não conseguisse o número de passagens necessárias para frequentar o Capsi na periodicidade proposta pela equipe, ou se o benefício não fosse estendido a cuidadores ou familiares, o projeto terapêutico ficava debilitado. Além disso, $o$ acesso se relaciona diretamente com a qualidade de vida dos familiares. Pesquisa com familiares de usuários de Caps I, II e III da região sul do Brasil revelou que a dificuldade de acesso foi um dos fatores associados à pior autoavaliação de sua qualidade de vida ${ }^{37}$.

\section{ESTRUTURA FÍSICA E FREQUÊNCIA}

As primeiras diretrizes elaboradas pelo Ministério da Saúde para funcionamento dos $\mathrm{Caps}^{\mathbf{3 8}}$, incluindo Capsi, afirmavam a necessidade de os projetos terapêuticos dos usuários serem compatíveis com as necessidades particulares de cada um, devendo os Caps organizarem processos de trabalho que atendessem à demanda de maior ou de menor intensividade do cuidado, o que se refletia também na frequência dos usuários aos serviços. Dado o mandato dos Caps/Capsi - atender casos de maior complexidade -, esperava-se que a frequência a esses serviços, ou o contato dos serviços com usuários, por meio de visitas domiciliares, ações nas comunidades e articulações territoriais, fosse maior do que apenas uma vez por semana. Quanto ao espaço, as mesmas diretrizes reforçavam que o Caps deve ter um ambiente estruturado com os recursos físicos necessários para atender a cada demanda, incluindo a alimentação dos usuários. Os familiares apontaram muitos problemas em relação a esses aspectos nos Capsi da Região Metropolitana do Rio:

Não tem o que oferecer mais porque, em primeiro lugar, lá precisa de uma reforma pra ontem [risos gerais]. Não tem como botar mais ninguém lá, e se não quiser reformar... (F13).

Quando chove é uma tristeza, quando faz sol é outro transtorno. [...] Só tem um banheiro. Aí quando o banheiro está interditado porque não tem água... (F14).

Não tinha água, água pros pacientes, quando você ia lá tinha que levar água pra dar pro seu filho. Agora que botaram um bebedouro lá, que nem sempre tem água [...]. (F15).

O único ar-condicionado que tinha foi retirado porque até a luz teve uma época que eles não estavam conseguindo pagar. [...] Então é uma água, um papel, alguma coisa, biscoito para as crianças... Porque tinha época que não tinha nem 
lanche para as crianças. Nem lanche! É muito difícil. Era muito precário. (F16).

Pesquisas avaliativas realizadas com gestores de Caps em Minas Gerais e no Rio Grande do Sul identificaram estruturas adequadas na maioria dos serviços, embora muitos funcionassem sem adaptações de acessibilidade. Em relação ao número de profissionais, encontraram carências em Caps I, mas não nos demais serviços ${ }^{29,35}$. Em outros estudos, os próprios familiares reconheceram melhoras na ambiência e na higiene dos serviços, mas também demonstraram insatisfação a respeito de aspectos da infraestrutura, falta de incentivo financeiro e de recursos humanos ${ }^{\mathbf{1 0 3 1}}$. Pesquisa realizada com profissionais de Caps II na Região Metropolitana de Porto Alegre (RS) constatou que problemas de estrutura levaram os trabalhadores a decidirem restringir temporariamente o acesso à unidade ${ }^{39}$. Tema semelhante foi abordado em nossa pesquisa pela mãe de um usuário, resultando na redução da frequência aos atendimentos. Houve, também, queixas em relação ao horário dos grupos, do espaço de espera e do tempo do atendimento da criança, que podem apontar para problemas temporários ou estruturais dos serviços.

Deveria ser um tempo maior. Deveria ser pelo menos três vezes na semana. Já chegou um ponto lá no Capsi, por falta de espaço lá, o tempo ficou de quinze em quinze dias. Depois ficou uma vez ao mês somente. Aí a gente reclamou. Porque uma vez ao mês não tem como. Tem que ter uma sequência, tem que ter uma rotina. (F14).

Você chegou lá no Capsi, seu filho entrou, você fica na rua, sentado, esperando! No meu caso, eu sou taxista e fico dentro do carro esperando Thora, Thora e meia. Se minha esposa for levar e eu não puder ir, ela fica lá na rua sentada, esperando. Não tem um espaço para você ficar! (F17).

Mas a maioria das mães, o tratamento mesmo em si é só meia hora, ficam lá sentadas aguardando. Meia hora só, não vale a pena você levar e voltar pra casa. (F2).
Vários familiares reconheceram o esforço dos profissionais e não os culparam pela situação 'precária' - palavra muito usada por eles. Houve um sentimento de empatia e compreensão que perpassava todos os relatos sobre o desempenho dos profissionais, a despeito dos problemas de estrutura e da falta ou sobrecarga dos trabalhadores.

Então tem que ter uma melhoria, tem que ter mais médicos, Dr. [nome do médico] fica sobrecarregado, eu fico com pena. Às vezes eu vou lá pra bater um papinho com ele, uma dúvida e tal, e está o cara lá com trinta pacientes na porta. Pô, que que é isso cara? (F3).

A realidade do espaço... gente, a precariedade! Nós temos os profissionais, a gente precisa é o espaço, e algo, que eles se comprometam com algo que nos dê essa garantia de deixar nosso filho. (F8).

Não tem um ventilador de teto, mosquito te devora, os espaços todos destruídos, a gente já vê que os profissionais estão exaustos, mas eles estão ali. (F8).

Fica claro que há uma lacuna entre as diretrizes e recomendações oficiais e a realidade dos serviços descrita pelos familiares. A efetiva implantação de uma rede articulada de serviços comunitários fica fortemente prejudicada quando a 'precariedade' se faz regra. Os Capsi saem em maior desvantagem nesse processo, devido à baixa cobertura desse dispositivo na maior parte do território nacional, quando comparada com os Caps ${ }^{40}$.

\section{Considerações finais}

No cenário de retrocesso político-econômico que o Brasil atravessa, com fortes prejuízos na sustentação do sistema público e universal da saúde, a maior atenção dos gestores e trabalhadores aos pontos de vista dos familiares dos usuários dos Caps pode ser estratégica para a preservação das conquistas da Reforma Psiquiátrica brasileira e para avançar na consolidação dos 
*Orcid (Open Researcher and Contributor ID). equipamentos de atenção psicossocial. Nesse sentido, entendemos que o discurso dos familiares de crianças e adolescentes autistas apontou para virtudes, problemas e desafios que - respeitadas as peculiaridades desse grupo - podem ser estendidas a muitos Caps e Capsi. Este artigo se dedicou a duas categorias encontradas nos discursos de familiares de autistas, o protagonismo e a participação no contexto do cuidado de seus filhos, e as barreiras encontradas para o acesso e continuidade do tratamento.

Em relação à primeira categoria, a pesquisa pode registrar o momento no qual parte dos familiares dos Capsi começava a valorizar a luta por direitos e a se envolver em distintas formas de ativismo. Se esse movimento, por um lado, parece seguir a trilha aberta pelas associações fundadas nas décadas anteriores, por outro, distingue-se delas pela demanda por políticas públicas de saúde que reconheçam o lugar do Capsi no cuidado qualificado aos autistas. Além disso, os familiares apontaram para a necessidade de maior iniciativa, de sua parte e dos serviços, para ampliar sua presença e envolvimento no tratamento, a partir do reconhecimento do seu sofrimento e necessidade de cuidado.

No caso das barreiras, os familiares não deixaram de relatar experiências positivas no acesso ao Capsi, mas também enfatizaram problemas diversos, envolvendo o transporte para chegar ao serviço, os horários e a frequência dos atendimentos, bem como a falta de manutenção e precariedade do espaço físico. Tais problemas dependem de variáveis territoriais, como o tamanho do bairro ou município, a eficiência da rede de transportes - no caso da Região Metropolitana do Rio de Janeiro, principalmente dos ônibus, mas também dos trens e metrô - e o suporte dado pela gestão local, mas os cenários descritos pelos familiares fluminenses encontram eco em outros serviços de distintos territórios, em diferentes cidades e estados brasileiros.

Finalmente, é importante destacar que a pesquisa possui limitações no que diz respeito à generalização dos achados, já que utilizou amostragem intencional (e não aleatória), justificada pela necessidade de um perfil amostral específico de familiares com vinculação e assistidos pelos Capsi por, no mínimo, seis meses. Tal escolha metodológica visava atender aos objetivos do estudo de investigar o envolvimento dos familiares no cuidado oferecido pelo serviço, além das dificuldades de acesso e de continuidade do cuidado que poderiam incidir em sobrecarga na lida com seus filhos.

O contexto de acirramento das diferenças políticas no país, que ainda não se apresentava de forma explícita no momento da realização desta pesquisa, tem seus correlatos no campo da saúde mental, fazendo com que as pautas das associações de familiares de autistas - especialmente a rejeição aos Caps e a demanda por terapias especializadas e serviços segregados - frequentemente conflitem com a direção do trabalho da atenção psicossocial no Sistema Único de Saúde (SUS). A aproximação entre gestores e trabalhadores dos Caps e Capsi e os familiares dos usuários desses serviços, autistas ou não, por meio da valorização de sua fala, do acolhimento de seu sofrimento e do estímulo e respeito a suas iniciativas de auto-organização, pode agregar novos aliados aos esforços de superação de obstáculos para o cumprimento do mandato psicossocial e de resgate da ética democrática e participativa no manejo da res publica na área da saúde mental no Brasil.

\section{Colaboradores}

Lima RC (0000-0002-8583-4535)*, Couto MCV (0000-0003-0926-8823)* e Andrada BC (0000-0003-2383-7797)* colaboraram igualmente para análise e interpretação dos dados, elaboração do rascunho e revisão crítica, e aprovação da versão final do manuscrito. Corrêa PH (0000-0002-0632-8694)* e Cardozo ACA (0000-0002-8852-0689)* contribuíram igualmente na elaboração do rascunho e revisão crítica e aprovação da versão final do manuscrito. 


\section{Referências}

1. Cascio A, Costa Andrada B, Bezerra Jr B. Reforma Psiquiátrica e serviços para o autismo na Itália e no Brasil. In: Fein E, Rios C, organizadores. Autismo em tradução: uma conversa intercultural sobre condições do espectro autista. Rio de Janeiro: Papéis Selvagens; 2019. p. 77-118.

2. Oliveira BC, Feldman C, Couto MCV, et al. Políticas para o autismo no Brasil: entre a atenção psicossocial e a reabilitaçãol. Physis. 2017; 27(3):707-726.

3. Barroso SM, Bandeira M, Nascimento E. Sobrecarga de familiares de pacientes psiquiátricos atendidos na rede pública. Rev psiquiatr clín. 2007; 34(6):270-277. [acesso em 2020 jan 6] Disponível em: http://www. scielo.br/pdf/rpc/v34n6/v34n6a03.pdf.

4. Delgado PG. Sobrecarga do cuidado, solidariedade e estratégia de lida na experiência de familiares de Centros de Atenção Psicossocial. Physis. 2014; 24(4):11031126.

5. Duarte MLC, Kantorski LP. Avaliação da atenção prestada aos familiares em um centro de atenção psicossocial. Rev Bras Enferm. 2011; 64(1):47-52.

6. Dimenstein M, Sales AL, Galvão, E. et al. Estratégia da Atenção Psicossocial e participação da família no cuidado em saúde mental. Physis. 2010; 20(4):12091226. Disponível em: http://www.scielo.br/pdf/physis/v20n4/a08v20n4.pdf.

7. Camatta MW, Schneider JF. O trabalho da equipe de um Centro de Atenção Psicossocial na perspectiva da família. Rev. Esc Enferm USP. 2009; 43(2):393-400. [acesso em 2020 fev 26]. Disponível em: http://www. scielo.br/pdf/reeusp/v43n2/a19v43n2.pdf.

8. Cunha C, Santos RGH, Carlos DM. O filho com transtorno global do desenvolvimento: percepções de mães acerca de cuidados cotidianos. REFACS. 2016; 4(2):98106.

9. Thiengo DL, Fonseca D, Abelha L, et al. Satisfação de familiares com o atendimento oferecido por um
Centro de Atenção Psicossocial Infantojuvenil (CAPSi) da cidade do Rio de Janeiro. Cad. Saúde Coletiva. 2015; 23(3):298-308.

10. Lima RC, Couto MC. Percepções sobre o autismo e experiências de sobrecarga no cuidado cotidiano: estudo com familiares de CAPSi da Região Metropolitana do Rio de Janeiro. Cad. Brasileiros Saúde Mental. 2020; 17;12(31):217-44.

11. Lima RC, Feldman C, Evans C, et al. Defesa de direitos e políticas para o autismo no Brasil e nos EUA. In: Fein E, Rios C, organizadores. Autismo em tradução: uma conversa intercultural sobre condições do espectro autista. Rio de Janeiro: Papéis Selvagens; 2019. p. 35-76.

12. Associação Brasileira de Autismo. História e atuação. [acesso em 2020 fev 26] Disponível em: http://www. autismo.org.br/site/abra/historia-e-atuacao.html.

13. Nunes F. Por amor e por direitos: as gramáticas do afeto e da política nas mobilizações públicas de familiares de autistas. Cad. Campo (São Paulo, 1991). 2016; 25(25):222-245.

14. Nunes F, Ortega F. Ativismo político de pais de autistas no Rio de Janeiro: reflexões sobre o "direito ao tratamento". Saude e Soc. 2016; 25:964-975.

15. Rios C. "Nada sobre nós, sem nós"? O corpo na construção do autista como sujeito social e político. Sex., Salud Soc. (Rio J.). 2017; (25):212-230.

16. Rios C, Costa Andrada B. The changing face of autism in Brazil. Cult Med Psychiatry. 2015; 39(2):213234.

17. Associação Brasileira para Ação por Direitos das Pessoas com Autismo (ABRAÇA). Manifesto público decreto de regulamentação da Lei dos Autistas. [acesso em 2020 fev 27]. Disponível em: http://abraca.autismobrasil.org/manifesto-publico-decreto-de-regulamentacao-da-lei-dos-autistas/. 
18. Kittay EF. When Caring Is Just and Justice Is Caring: Justice and Mental Retardation. Public Cult. 2001; 13(3):557-579.

19. Rios C. Expert em seu próprio filho, expert em seu próprio mundo - reinventando a(s) expertise(s) sobre o autismo. In: Rios C, Fein E, organizadores. Autismo em Tradução- uma conversa intercultural sobre condições do espectro autista. Rio de Janeiro: Papéis Selvagens; 2019. p. 231-257.

20. Presotto RF, Silveira M, Delgado PGG, et al. Experiências brasileiras sobre participação de usuários e familiares na pesquisa em saúde mental. Ciênc. Saúde Colet. [internet]. 2013 [acesso em 2020 ago 14]; 18(10):2837-2845. Disponível em: http://www. scielo.br/scielo.php?script=sci_arttext\&pid=S1413$-81232013001000008 \& \operatorname{lng}=$ pt. http://dx.doi. org/10.1590/S1413-81232013001000008.

21. Alves TC, Oliveira WF, Vasconcelos EM. A visão de usuários, familiares e profissionais acerca do empoderamento em saúde mental. Physis [internet]. 2013 [acesso em 2020 ago 14]; 23(1):51-71. Disponível em: http://www.scielo.br/scielo.php?script=sci arttext\&pid=S0103-73312013000100004\&lng=pt. http://dx.doi.org/10.1590/S0103-73312013000100004.

22. Brasil. Ministério da Saúde. Saúde mental no SUS: os centros de atenção psicossocial Brasília, DF: Ministério da Saúde; 2004.

23. Vechiatto L, Alves AMP. A saúde mental infanto-juvenil e o Caps-I: uma revisão integrativa (Mental Health Children and youth and Caps-I: an integrative review). Emancipação. 2019; 19(1):35-47.

24. Machineski GG, Schneider JF, Camatta MW. O tipo vivido de familiares de usuários de um centro de atenção psicossocial infantil. Revista Gaúcha de Enfermagem. 2013; 34(1):126-132.

25. Patriota LM, Silva FS, Lima FEBC. Uma análise das concepções dos familiares dos usuários do Centro Campinense de Intervenção Precoce (CAP$\mathrm{Si}$ ) acerca do tratamento realizado no serviço. In: Anais da $4^{\text {a }}$ Jornada Internacional de Políticas Pú- blicas. [acesso em 2020 fev 25]. Disponível em: http://www.joinpp.ufma.br/jornadas/joinppIV/ OLD/eixos_OLD/12.\%20Impasses\%20e\%20Desafios\%20das\%20Politicas\%20de\%20Seguridades\%20Social/UMA\%20ANALISE\%20DAS\%20 CONCEP\%C3\%87\%C3\%95ES\%20DOS\%20FAMILIARES\%20DOS\%20USU\%C3\%81RIOS\%20DO\%20 CE.pdf.

26. Araújo GH, Saraiva AM, Carvalho MA, et al. Estratégias de cuidado desenvolvidas no CAPS infantil: concepções de familiares e profissionais. Rev. Pesqui. (Univ. Fed. Estado Rio J., Online). 2015; 7:28-38.

27. Távora RCO, Monteiro ARM, Tavares SFV, et al. Atendimento de crianças e adolescentes em CAPSi: visão dos familiares. Rev. Pesqui. (Univ. Fed. Estado Rio J., Online). 2010; 2(supl):697-700.

28. Cunha C, Santos RGH, Carlos DM. O filho com transtorno global do desenvolvimento: percepções de mães acerca de cuidados cotidianos REFACS. 2016; 4(2):98106.

29. Silva SN, Lima MG. Avaliação da estrutura dos Centros de Atenção Psicossocial da região do Médio Paraopeba, Minas Gerais. Epidemiologia e Serviços de Saúde. 2017; 26:149-60.

30. Kantorski LP, Machado RA, Lemões MA, et al. Avaliação da estrutura e processo na visão dos familiares de usuários de saúde mental. Ciênc. cuid. saúde. 2012; 24:11(1):173-80.

31. Lima RC, Couto MC, Delgado PG, et al. Indicadores sobre o cuidado a crianças e adolescentes com autismo na rede de CAPSi da região metropolitana do Rio de Janeiro. Physis. 2014; 24(3):715-39.

32. Lima RC, Couto MC, Solis FP, et al. Atenção psicossocial a crianças e adolescentes com autismo nos CAPSi da região metropolitana do Rio de Janeiro. Psicol. soc. 2017 ; 26:196-207.

33. Model LR, Peixoto MJR, Caeran J, et al. Olhar voltado para cuidadores - avaliando a qualidade de vida e características relacionais de cuidadores de crianças 
e adolescentes em tratamento em CAPS Infantil. In: Anais do $12^{\circ}$ Salão de Iniciação Científica; 03 a 07 de outubro de 2011; Porto Alegre, Brasil. Porto Alegre: Pontifícia Universidade Católica do Rio Grande do Sul; 2011.

34. Dombi-Barbosa C, Neto MM, Fonseca FL, et al. Condutas terapêuticas de atenção às famílias da população infantojuvenil atendida nos centros de atenção psicossocial infantojuvenis (CAPSI) do estado de São Paulo. Journal of Human Growth and Development. 2009; 19(2):262-8.

35. Leal BM, De Antoni C. Os Centros de Atenção Psicossocial (CAPS): estruturação, interdisciplinaridade e intersetorialidade. Aletheia. 2013 [acesso em 2020 out 9]; (40). Disponível em: http://www.periodicos. ulbra.br/index.php/aletheia/article/view/3344.

36. Schmidt MB, Figueiredo AC. Acesso, acolhimento e acompanhamento: três desafios para o cotidiano da clínica em saúde mental. Revista Latinoamericana de Psicopatologia Fundamental. 2009; 12(1):130-40.
37. Kantorski LP, Jardim VM, Treichel CA, et al. Fatores associados a uma pior avaliação da qualidade de vida entre familiares cuidadores de usuários de Centros de Atenção Psicossocial. Cad. Saúde Coletiva. 2017; 25(4):460-7.

38. Brasil. Ministério da Saúde. Saúde mental no SUS: os centros de atenção psicossocial. Brasília, DF: Ministério da Saúde; 2004.

39. Scheibel A, Hecker Ferreira L. Acolhimento no CAPS: reflexões acerca da assistência em saúde mental. Rev. baiana saúde pública. 2011; 35(4):966.

40. Brasil. Ministério da Saúde. Saúde Mental em Dados - 12, ano 10, $\mathrm{n}^{\mathrm{o}}$ 12. Informativo eletrônico. Brasília, DF: Ministério da Saúde; 2015 [acesso em 2019 ago 20]. Disponível em: www.saude.gov.br/bvs/saudemental.

Recebido em 01/03/2020

Aprovado em 25/08/2020

Conflito de interesses: inexistente

Suporte financeiro: não houve 